\title{
ASPECTOS ESENCIALES PARA UNA EFECTIVA REFORMA A LA JUSTICIA PENAL
}

David Espinosa Acuña*

Resumen: En el año 2020 se cumplieron quince años de la implementación del proceso penal de tendencia acusatoria en Colombia. La implementación de la Ley 906 de 2004 supuso un verdadero cambio de paradigma, que ha sido acogido por nuestra sociedad adecuadamente. Sin embargo, es muy importante realizar un análisis retrospectivo con el propósito de evaluar qué ha funcionado óptimamente y qué aspectos merecen ser traídos al orden del día para mejorar la praxis judicial colombiana. Este artículo pretende poner en discusión algunos aspectos sobre los cuales no se habla mucho, pero que renovarían el funcionamiento de nuestro proceso penal.

Palabras clave: reforma a la justicia; tecnología; elección de jueces; audiencias; Administración; Rama Judicial; pena; Código Penal.

* Abogado egresado de la Facultad de Derecho de la Universidad de La Sabana (Bogotá, Colombia) y visiting scholar de la Escuela de Derecho de la Universidad de Puerto Rico, Recinto de Río Piedras. Correo-e: david_espinosa@hotmail.com.Fecha de recepción: 24 de enero de 2020. Fecha de aceptación: 12 de enero de 2021. Para citar el artículo: DAVID EsPINOSA ACUÑA. "Aspectos esenciales para una efectiva reforma a la justicia penal”, Revista Derecho Penal y Criminología, vol. 41, n. ${ }^{\circ} 110$, enerojunio de 2020, Bogotá, Universidad Externado de Colombia, pp. 35-55. DOI: https://doi.org/10.18601/ 01210483.v41n110.03. 


\title{
ESSENTIAL ASPECTS FOR AN EFFECTIVE PENAL JUSTICE REFORM
}

\begin{abstract}
In 2020, fifteen years have passed since the implementation of the criminal process with an accusatory tendency in Colombia. The implementation of Law 906 of 2004 supposed a true paradigm shift, which has been adequately embraced by our society. However, it is very important to carry out a retrospective analysis in order to evaluate what has worked optimally and what aspects deserve to be brought to the agenda to improve Colombian judicial practice. This article tries to put into discussion some aspects about which not much is said, but which would renew the operation of our criminal process.
\end{abstract}

Keywords: justice reform; technology; election of judges; court hearing; Administration; penalty; Criminal Code.

La principal razón de la vida en sociedad es la justicia. Ya lo decían los contractualistas cuando explicaban que la única justificación para someternos al poder de un monstruo imaginario llamado Estado es que éste no permitirá que el más fuerte abuse del más débil.

Conseguir que todo ciudadano tenga el convencimiento y la tranquilidad intrínsecos de que el establecimiento hará respetar sus derechos es el más básico y a la vez el más completo concepto de la administración de justicia. En esa medida, el Estado debe hacer un esfuerzo superior por garantizar esa promesa de justicia que es, en últimas, su razón de ser. Y esa legítima aspiración ciudadana debe, por supuesto, estar enmarcada en las premisas de eficacia y eficiencia.

Reflexiones como las anteriores, en tiempos actuales, nos conminan a inquirir por qué seguimos viviendo en sociedad cuando nuestra realidad judicial se aparta cada vez más del propósito fundamental que justifica la existencia del Estado.

Partiendo de esa penosa conclusión colectiva -y siendo conscientes de la inviabilidad de desmontar la vida en sociedad-, surge indiscutible la urgencia de una reforma judicial que conduzca a una administración de justicia pronta y cumplida, percibida como tal por el conjunto de los ciudadanos.

Para facilidad de la exposición, y por tratarse también del área de especialidad académica y profesional del autor, en este documento se utilizará como referente la administración de justicia en materia penal (aunque en algunos puntos lo que acá se exponga aplicará a todas las jurisdicciones).

Sea lo primero distinguir el acto de hacer justicia (de dar a cada quien lo suyo) del aparataje que se disponga para que los funcionarios judiciales puedan hacer justicia. 
Con esta diferenciación en mente, encontraremos (1) actuaciones reservadas para los jueces, (2) actuaciones propias de expertos en métodos y administración y (3) actuaciones en donde necesariamente deberán confluir ambos roles.

Sobre esta línea, el presente documento llamará la atención en aquellos puntos que mayor sensibilidad generan en el litigio cotidiano y cuyo acatamiento propendería a optimizar la justicia de nuestro país: separación entre jueces y administradores de la judicatura, reducción de estadios procesales, reducción de intervinientes en el proceso, concreción de infracciones penales, revaluación de la penología, modernización de planta física, entre otros.

\section{SOBRE LOS JUECES}

Dentro de la denotada primacía que encuentra la justicia en el modelo estatal, la figura del juez es igualmente predominante. El juez es quien debe, en la sociedad, encargarse de la tarea de determinar qué es lo justo y darle a cada quien su derecho.

No está demás señalar que el funcionario judicial debe ser una persona "superior" dentro de la sociedad y, en tal sentido, la selección de ellos debe estar determinada a encontrar esa superioridad en quienes aspiran a esa dignidad. A eso llamaremos la búsqueda del "jurisprudente".

Para detenernos en lo anterior, de las virtudes cardinales (que son sin duda el eje del ser humano) se encuentran dos imprescindibles en tratándose de la judicatura: la justicia y la prudencia. Y se atiende a las virtudes porque éstas son aquellos hábitos operativos que perfeccionan al ser humano.

La búsqueda de ese ciudadano "superior" no debe limitarse a la de sus conocimientos de la ley (que por supuesto se deben verificar) sino en encontrar en los aspirantes unas condiciones particularísimas que los definan: deben ser hombres realmente virtuosos en la justicia y en la prudencia.

El juez debe ser una persona que tenga por hábito el respeto al derecho. Una persona a quien le resulte natural el acto de la justicia. Y para ello su proceder debe estar desprovisto de cualquier consideración ideológica, política o religiosa. Sus condicionamientos morales deben hacerle indemne a cualquier tentación que le desvíe de dar a cada quien lo suyo.

Pero lo anterior es imposible si el aspirante a juez no es un virtuoso en la prudencia, pues sólo a través de ésta -con sus elementos cognitivo y volitivo- se garantizará la casi innata disposición de establecer qué corresponde a cada quien para, luego, otorgarlo en el acto de administrar justicia. 
Claro lo anterior, habrá de diseñarse un procedimiento de selección, independiente de la colegiatura, que tenga como único propósito encontrar a estos selectos ciudadanos que puedan, de manera ejemplar, cumplir con esta función que sustenta la vida en sociedad. Y para ello la ingeniería resulta la aliada más imparcial en el establecimiento de métodos que logren este propósito de manera objetiva, como se explicará más adelante.

Sin duda, no estará de más aplicar estos mismos criterios para aquellos que ostenten el rol de la persecución penal (y en general para todos los servidores públicos, aunque seguramente con otras virtudes). Pero si de priorizar se trata, el mayor esfuerzo estatal al establecer una ingeniería de selección debe enfocarse en quienes aspiren a ser llamados jueces.

\section{SOBRE LA ADMINISTRACIÓN}

Teniendo absoluta claridad de que la función judicial será ejercida por estos virtuosos doctos en la ley, el Estado habrá de disponer los mecanismos estructurales para que aquellos cuenten con las condiciones idóneas para operar. Y esa premisa aspiracional debe partir de descargar a estos "superiores" de cualquier función distinta a la de ejercer la justicia. Distraerlos en cualquier otro menester imposibilitaría la expectativa de que estén desprovistos de intereses ajenos a su rol.

Si se acepta lo anterior, el Estado habrá de suplir todas aquellas tareas que viabilicen un escenario operativo para los jueces y es allí donde la ingeniería debe entrar a cooptar todo aquello que tenga siquiera un atisbo distractor para el funcionario judicial.

En esa lógica, lo primero que deberá atender esta entidad "administradora” es el asunto de la selección. Se deberá determinar un grupo específico de funcionarios administrativos que establezcan mecanismos de verificación estrictos (se trata de escoger a las personas más importantes de la sociedad) respecto del conocimiento jurídico y de las condiciones particulares que se esperan de los aspirantes a juez (a saber, que sean justos y prudentes).

Estos procedimientos, que deben estar atados a los desarrollos tecnológicos, deberán escudriñar exhaustivamente las competencias y cualidades personales de los aspirantes. Deberán indagar sobre sus antecedentes históricos, sobre sus conocimientos actuales, sobre sus condiciones morales y sobre su perfil psíquico. Ningún esfuerzo se debe escatimar en esta búsqueda, pues son estas personas quienes han de garantizar la viabilidad del Estado de derecho.

Visto desde esta óptica, y por elemental que parezca, resulta incomprensible que hoy la función selectora esté en manos de los mismos operadores judiciales. ¿Cómo no esperar en ellos algún interés con el actual diseño normativo? Esto se tiene que terminar. 
Pero una vez elegidos los jueces, y asegurando que estos sean lo mejor de la sociedad, quedan otras muchas tareas que deben ser asumidas por la entidad administradora, pues en últimas el ropaje estructural requerido para la actividad judicial no difiere en mucho del de cualquier empresa, así aquella carezca de ánimo lucrativo. En ese sentido, el manejo financiero y presupuestal, la planta de personal, el mantenimiento de las múltiples plantas físicas, la administración de los insumos de trabajo, la disposición de las salas de audiencia y, en general, todo lo que se pueda asociar al concepto de back office, deben ser asuntos completamente ajenos a los jueces.

Mantener la posibilidad de que los jueces participen en las labores puramente administrativas, que por esencia les son ajenas, hace inevitable que la sociedad reproche el asomo de interés.

Conseguido el alejamiento de los jueces de sus tareas antinaturales, la tecnología resultará la mejor aliada de la entidad administrativa para lograr que el escenario procesal funcione de la mejor manera. El apoyo en herramientas sistematizadas diseñadas por la ingeniería no sólo logrará imprimir celeridad al procedimiento, sino que lo proveerá de objetividad minimizando las posibilidades de la manipulación humana guiada por intereses particulares.

Piénsese, por ejemplo, en la posibilidad de presentar la noticia criminal mediante medios electrónicos con formatos detalladamente diseñados, que permitan al sistema operativo identificar elementos esenciales de lo denunciado o querellado para que el reparto proceda de manera automática al funcionario competente ${ }^{1}$, en el cual se puedan incluir como datos adjuntos todos los anexos que deseen acompañarse y con medios de identificación electrónica ciertamente severos que minimicen la posibilidad del anonimato mediante herramientas que ya están presentes en el mercado tecnológico.

De igual manera, ese reparto podría generar inmediatamente una carpeta electrónica (como ocurre actualmente en Brasil para no ir muy lejos), que podrá ser reservada dependiendo de la etapa procesal en que se encuentre y a la cual sólo deberán tener acceso las personas que el funcionario persecutor autorice mediante contraseñas, previa acreditación de su respectivo rol. Dicha carpeta será alimentada por el ente acusador con el diseño de un programa metodológico, las órdenes a policía judicial y las resultas de las tareas investigativas, así como por las contribuciones que haga quien ostente la calidad de representación de la víctima. Pensar en esta posibilidad significaría que un descubrimiento probatorio sería tan sencillo como otorgar, en el momento pertinente, la contraseña de acceso a la carpeta (excluyendo por supuesto aquello que legalmente no deba ser objeto de descubrimiento).

1 En la actualidad una noticia criminal puede tardar semanas, e incluso meses, para ser sometida a reparto y otro tanto para que llegue al funcionario seleccionado. 
Del mismo modo, las solicitudes de audiencia podrían realizarse a través de internet, vinculándolas a un software en donde estén inscritos todos los profesionales del Derecho y en el que se lleve registro de las diligencias que tienen programadas por todos los despachos judiciales, logrando de este modo evitar que se presente el recurrente escenario en el que los abogados excusen su comparecencia alegando tener otras audiencias programadas a la misma fecha y hora.

Sobre esta misma lógica, la radicación del escrito de acusación y la programación de las siguientes audiencias se podrán realizar a través del sistema operativo que la ingeniería establezca, pudiéndose verificar electrónicamente la recepción del mensaje una vez que el receptor lo abra declarándose surtida la notificación. Incluso podrían establecerse alarmas que llamen prudentemente la atención al sistema cuando haya transcurrido determinado tiempo sin que el destinatario de la citación la haya abierto, para propender por medios de notificación supletivos. Lo anterior sin perjuicio de la responsabilidad de los sujetos procesales de su compromiso de hacer fiel seguimiento a las citaciones del sistema como un factor connatural a sus deberes profesionales.

Siguiendo esta línea, el desarrollo tecnológico también debe tener incidencia en la infraestructura de las salas de audiencia (que, por cierto, empresas colombianas ya tienen desarrollado). Imagínese que en las mesas de los sujetos procesales y del testigo, el micrófono esté dotado de un sistema de reconocimiento dactilar que permita la plena identificación de los intervinientes, asociada al software que almacene la base de datos y que ese mismo micrófono esté asociado a un sistema de reconocimiento de voz que permita la transliteración en tiempo real de cada uno de los intervinientes dejando registro en tiempo real de lo que se diga en cada una de las audiencias, facilitando no sólo el trabajo posterior del juez de instancia, sino también el de todas las partes e intervinientes. Transliteración que subiría de manera automática a la carpeta electrónica que todos podrían consultar, junto con los elementos que van siendo decretados en las audiencias preparatorias o que son introducidos como prueba el discurrir del juicio oral, etcétera.

Sin duda, una unidad administradora fundada en la ingeniería y soportada en la tecnología podría ofrecer un sinfín de soluciones que hoy en día escapan incluso al imaginario de los litigantes.

\section{SOBRE EL PROCEDIMIENTO}

Además de garantizar la competencia y probidad de los jueces y profesionalizar la administración independiente que hace posible el buen ejercicio judicial, no puede perderse de vista que el escenario natural de determinación de lo que corresponde a cada quien es el proceso judicial.

Es un derecho fundamental de primera generación que la decisión judicial sea el resultado de un debido proceso. Y éste debe estar revestido de garantías que se 
traduzcan en transparencia y que ofrezca a los intervinientes, y a la comunidad en general, la certidumbre de que el resultado consignado en una sentencia es un acto de justicia al que se llegó luego de un debate probatorio.

Esto debe resaltarse: la decisión judicial, además de proba y transparente, debe ser eficaz, debe llegar a tiempo. De cualquier otra manera no se tratará de un verdadero acto de justicia.

A propósito de este requisito de prontitud, de cuya ausencia se queja nuestra sociedad al unísono, la reforma en que se debe encaminar el establecimiento debe concentrar su atención en hacer que el escenario procesal adopte una dinámica que, sin escatimar en garantías, agilice los estadios para avocar la atención judicial en lo que realmente interesa en una discusión de esta naturaleza y produzca resultados con celeridad.

Y en esta materia (que conjuga lo jurídico y lo administrativo) la academia y la experiencia litigiosa dan cuenta de una serie de propuestas que podrían alivianar el discurrir procesal sin sacrificar en ningún momento la profundidad que supone el examen y la determinación de la responsabilidad de un individuo.

Pero antes de la exposición de esas propuestas, no puede dejar de mencionarse algo que resulta trascendental para la eficacia y eficiencia de la administración de justicia, específicamente en el ámbito penal: nuestro actual sistema procesal está diseñado para que sólo un porcentaje mínimo de las noticias criminales lleguen a la instancia del juicio oral. La mayoría de los procesos debería concluir de manera anticipada con mecanismos que garanticen la sensación de justicia. Y el responsable de que ello sea así es, en esencia, el ente persecutor. De la excelencia en su rol investigativo y acusatorio depende el éxito del sistema penal.

Con estas consideraciones en mente, entremos en materia:

\section{- $\quad$ Reducción de audiencias}

\section{- $\quad$ Análisis previo de la Fiscalía}

Todo proceso penal se inicia por una noticia criminal. A partir de ella el fiscal debe adelantar una etapa de indagación preliminar en desarrollo de un programa metodológico de investigación que debió haber preparado en conjunto con su par experto en pruebas: el policía judicial, a cuyo cargo está la ejecución de dicho programa.

El resultado de esta indagación preliminar debe llevar al instructor a una única conclusión: tengo caso o no tengo caso. Si no tiene caso, debe archivar; si lo tiene, debe presentarlo ante la judicatura. 
No existe ninguna duda de que el mayor represamiento del sistema está en esta primera etapa. Es inverosímil que las noticias criminales reposen por años en los despachos sin tener la premura propia de un límite temporal distinto a la prescripción (que no es premura alguna). Esta situación se hace evidente si se compara el número de noticias criminales que se presentan y la cantidad de imputaciones realizadas en los mismos períodos ${ }^{2}$ :

\begin{tabular}{|c|c|c|}
\hline Año & Noticias criminales & Formulación de imputación \\
\hline 2005 & 184.140 & 8630 \\
\hline 2006 & 398.353 & 27.236 \\
\hline 2007 & 603.106 & 43.018 \\
\hline 2008 & 716.925 & 54.318 \\
\hline 2009 & 964.143 & 66.070 \\
\hline 2010 & 980.459 & 76.598 \\
\hline 2011 & 1.034 .042 & 81.599 \\
\hline 2012 & 1.041 .634 & 21.979 \\
\hline 2013 & 1.114 .638 & 19.373 \\
\hline 2014 & 1.084 .712 & 80.053 \\
\hline 2015 & 1.123 .028 & 91.621 \\
\hline 2016 & 1.151 .917 & 103.523 \\
\hline 2017 & 1.212 .162 & 109.579 \\
\hline 2018 & 1.240 .216 & 106.002 \\
\hline & & \\
\hline
\end{tabular}

Las cifras son dramáticas, incluso si se compara con el primer semestre de 2019, pues basta realizar una confrontación entre el número de indagaciones preliminares y de investigaciones en la misma época para comprender que la eficiencia del sistema con esta clase de números resulta, cuando menos, una utopía:

\begin{tabular}{|c|c|c|}
\hline Año/Mes & Indagaciones & Investigaciones \\
\hline $2019-1$ & $79.227,00$ & 1168,00 \\
\hline $2019-2$ & $82.179,00$ & 1522,00 \\
\hline $2019-3$ & $90.079,00$ & 2541,00 \\
\hline $2019-4$ & $78.483,00$ & 2916,00 \\
\hline $2019-5$ & $88.350,00$ & 4032,00 \\
\hline $2019-6$ & $25.271,00$ & 1040,00 \\
\hline
\end{tabular}

2 Fiscalía General de la Nación. Respuesta a derecho de petición de radicado n. ${ }^{\circ} 20196110164972$, oficio SPPEI-10210. 
En el mes de junio del año 2011, la Ley 1453 intentó poner un límite de tiempo a esta etapa preprocesal, de dos o tres años, dependiendo de algunas condiciones. Sin embargo, esta ley, hoy vigente, simplemente no se aplica por dos razones: un defecto legislativo (se trata de un supuesto fáctico sin consecuencia jurídica) y la imposibilidad física de su cumplimiento (por la congestión en los despachos de la Fiscalía, que me consta es real).

Dada esta coyuntura, y tratándose del problema estadísticamente más significativo, el esfuerzo estatal debe intensificarse en esta etapa.

Es indispensable que esta etapa preprocesal tenga un plazo de tiempo perentorio, y el actuar de la Fiscalía General de la Nación debe orientarse a destrabar esta situación, que es de su exclusiva competencia.

Sin duda, remedios directos que no requieren de ningún trámite legislativo y que se habrán de fundar en la creatividad interna de la Fiscalía serán los más inmediatos, aunque, por supuesto, no serán suficientes.

El desmonte de una estructura jerárquica compleja de personal en el ente persecutor y el máximo aprovechamiento de la planta humana en la función propia de los fiscales alivianarían la extenuante carga de esos pocos que siguen actuando como tal (investigando y acusando).

Si lo anterior se combina con una directriz que unifique y promueva el rol del acusador privado (con algunas precisiones que se expondrán más adelante), serán aún mayores los efectos inmediatos de descongestión.

Por supuesto, la responsabilidad no puede toda recaer sobre la Fiscalía. El incremento de personal que requiere el ente acusador (tanto de fiscales como de investigadores) habrá de apalancarse en criterios presupuestales y también en iniciativas legislativas que propendan por que los partícipes del proceso penal estén limitados al mínimo necesario.

En suma: hay que dotar a la Fiscalía de las herramientas necesarias para solucionar el mayor foco de congestión del sistema judicial que es la etapa de indagación preliminar. Sólo con esas herramientas se podrá exigir un imperativo temporal serio que conmine al persecutor a discernir de manera pronta qué casos deben ser llevados ante un juez y cuáles deben ser archivados (por certeza en su atipicidad-como existe actualmente- o por inviabilidad probatoria contrastable con un esfuerzo real de investigación documentada; $y$, en ambos casos, con reactivación frente a prueba sobreviniente, potencializando el rol del apoderado de víctimas sólo en esta etapa). 
Gráficamente $^{3}$, podemos advertir la inmensa diferencia que tiene el concepto de indagación preliminar y las subsiguientes etapas procesales, lo cual implica necesariamente concluir que es en esta etapa en donde más incidencia y efectividad se debe tener para evacuar los asuntos, bien sea decidiendo formular imputación o archivar las diligencias.

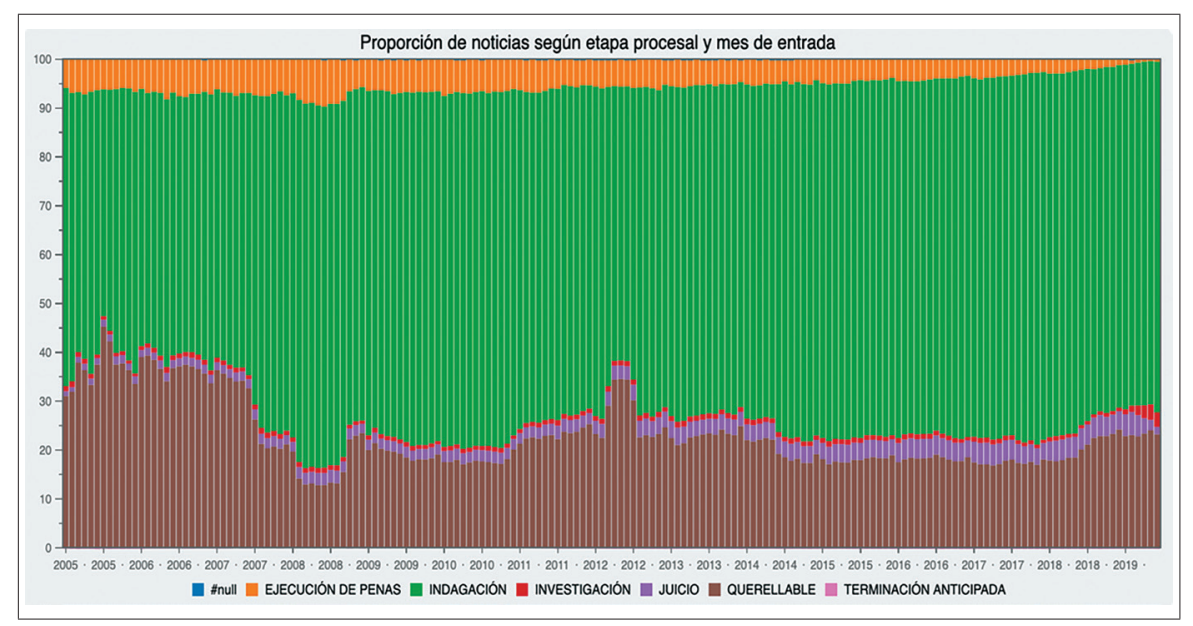

Lo único claro es que el ciudadano requiere una respuesta a su noticia criminal en un tiempo razonable, situación que actualmente no ocurre.

\section{- Formulación de imputación - descubrimiento probatorio - control material - audiencia preparatoria}

Llevar un caso ante la jurisdicción por parte del fiscal supone la convicción intrínseca de tener un caso. Y en la actualidad esa convicción se realiza ante un juez de control de garantías en la audiencia de formulación de imputación.

Sobre esta audiencia, que sólo existe en nuestro ordenamiento, se ha dicho bastante: de su origen, se sostiene que es el resultado de una malinterpretación del Pacto de Nueva York y del Pacto de San José; y de su objeto, que es un acto de notificación que activa simbólicamente el derecho de defensa pero que carece de control material judicial porque, aunque se insiste en que el juez de garantías no es un "convidado de piedra", su naturaleza de acto de parte impide que el juez deniegue una imputación.

3 Fiscalía General de la Nación. Proporción de noticias según etapa procesal y mes de entrada [en línea] [fecha de consulta: 1. ${ }^{\circ}$ de mayo de 2019] Disponible en [https://www.fiscalia.gov.co/colombia/ noticia-criminal/]. 
Sobre esa base, y propendiendo a la eficiencia y la eficacia, ¿qué garantía se afectaría si la convicción del fiscal se llevara directamente a una audiencia de acusación, previo traslado del escrito de acusación? Al ir directamente a una audiencia de acusación independientemente del acto de parte, el juez puede realizar un control material efectivo de la acusación para, una vez superado, proceder inmediatamente al descubrimiento probatorio. La etapa de la audiencia de imputación no cumple ninguna función sustancial en el proceso; de hecho, contribuye a la equivocada percepción de que la decisión de parte del fiscal que acusa cuenta con la concurrencia del juez. Con la eliminación de la audiencia de imputación, que es perfectamente prescindible, se contribuye a la descongestión del sistema.

Además, nada impide que la audiencia de acusación esté precedida, de ser necesario, por una legalización de captura, o que después de ella se solicite una medida de aseguramiento.

Ahora bien: es igualmente necesario que la Fiscalía modifique sus políticas de solicitud de captura y de medidas de aseguramiento limitándolas a aquellos casos en que resulten realmente necesarias, llevando a la práctica el mandato de que la pérdida de la libertad por razones preventivas debe ser la excepción y no la regla. Esto, además de salvaguardar las libertades constitucionales, la presunción de inocencia y el principio de igualdad de armas que es connatural al proceso adversarial, contribuiría de paso a la descongestión carcelaria.

Sería también importante que la audiencia preparatoria fuera atendida por un juez de control de garantías, de manera que el juez de conocimiento llegue completamente descontaminado a la audiencia de juicio oral. Esta es otra medida de descongestión que contribuye a garantizar la imparcialidad del fallador y su concentración exclusiva en el debate probatorio.

En la audiencia preparatoria, el juez de garantías podría plenamente hacer un análisis de conducencia, pertinencia, utilidad y razonabilidad (o sólo de pertinencia, cómo parece ser la reciente y afortunada inclinación jurisprudencial) o un análisis de inadmisión, rechazo o exclusión del material probatorio, teniendo como único referente la acusación que presente el persecutor.

Siguiendo la lógica de celeridad sin sacrificar garantías, ¿qué impediría que los descubrimientos probatorios de las partes se realizaran por escrito (subiéndolos a la carpeta electrónica) e incluso que las solicitudes probatorias también fueran radicadas documentalmente fuera de audiencia? Con esto los debates orales en torno a la preparación probatoria se concentrarían solamente en los aspectos que ameriten una verdadera contradicción: oposiciones a las solicitudes probatorias e impugnación a la negativa del decreto. 
Esta modificación sugerida, de ninguna manera desnaturalizaría el proceso penal respecto de su carácter oral, pues lo que se lograría sería concretar el objeto de la audiencia preparatoria, centrando la atención de los sujetos procesales en los aspectos que realmente generan debate entre ellos.

\section{- Conciliación preprocesal}

Otro de los puntos vivenciales que la academia y el litigio muestran como inconvenientes (sin desconocer las bondades de la figura de la conciliación) es que frente a la escasez de funcionarios de la Fiscalía y frente a lo prolongado y tortuoso del procedimiento, hoy sigan existiendo fiscales destinados de manera exclusiva a atender audiencias de conciliación.

Lo anterior no solo significa desaprovechar a un importantísimo número de funcionarios que podrían estar fungiendo como verdaderos fiscales, sino que, además, enfrenta a los querellantes a una prolongación absurda de los términos a los que se tiene que someter en procura de sus derechos.

Esto debe cambiar. Una vez recibida la noticia criminal, el fiscal debe analizar el caso y si encuentra que no tiene mérito, archivar; y si tiene mérito, debe radicar el escrito de acusación dejando constancia de que al inicio de la audiencia de acusación se les preguntará a las partes si tienen o no ánimo conciliatorio y, en caso de tenerlo, cuál es su fórmula de terminación anticipada.

Por supuesto, esto debe ir acompañado de una reforma legislativa que module la conciliación como requisito de procesabilidad de los delitos querellables para permitir al fiscal investigar sobre la viabilidad del caso y concluir rápidamente cuáles deben ser archivados. Esto sobre la base de que en los delitos querellables la verificación de los elementos estructurales es objetivamente menos compleja.

No obstante lo anterior, debe ser regla general de la Fiscalía delegar todos los delitos querellables en cabeza del acusador privado, incluso con apoyo de la defensoría pública para querellantes sin recursos. Esta política, acompañada del control material judicial, puede agilizar el proceso penal de manera significativa.

\section{- $\quad$ Recursos en directo}

Otro de los puntos que más han entorpecido la agilidad del proceso, y que fue una alteración del texto legislativo original, es el hecho de tener que sustentar los recursos de alzada ante el a quo, para que luego éste envíe el registro al superior y aquel resuelva algún día. Esto atenta contra la lógica de oralidad propia del sistema, pero además genera múltiples inconvenientes prácticos, como las interpelaciones del a quo que ve reprochada su decisión por el recurrente. 
Cuánta celeridad se generaría si se sustentara -como ocurría originalmente-el recurso directamente ante el ad quem. Esa inmediatez del expositor ante quien va a tomar la decisión -abriendo incluso la puerta para que los de segunda instancia puedan hacer preguntas al recurrente como ocurre en otras latitudes- no sólo dotaría de celeridad las decisiones (que deben ser tomadas, hasta donde sea posible, en esa misma audiencia), sino que enaltecería las garantías y el sentido del recurso.

\section{- $\quad$ Reducción de partícipes}

\section{- $\quad$ Necesidad de personal - Ministerio Público y representantes de víctimas}

Absolutamente nadie discute que la carga actual de los jueces, fiscales e investigadores es inmanejable. En ese sentido, una solicitud de incremento de personal parecería ser la más evidente de las soluciones, pero dista de ser la única.

Hoy en día existen unos intervinientes especiales que, sin importar hacia dónde inclinen su postura, inevitablemente rompen el equilibrio propio que supone un debate de adversarios. En un sistema de partes, en donde la tesis acusatoria se enfrenta a la tesis defensiva frente un árbitro imparcial, cualquier invitado adicional está de más.

Téngase en cuenta que la participación de esta entidad no resulta ser una constante en la práctica, aunque sí se encuentran habilitados para hacer presencia cuando a bien lo tengan. Esto toma mayor relevancia si tenemos en cuenta que, según la misma Procuraduría General de la Nación, el país cuenta con 208 procuradores judiciales II para asuntos penales y 149 procuradores judiciales I delegados para iguales asuntos en todo el país, esto, incluyendo los procuradores judiciales de apoyo a víctimas (Ley 1448 de 2011).

Por esa razón es indebido mantener en los debates orales la presencia de un representante del Ministerio Público cuyas intervenciones no sólo prolongan los procedimientos, sino que desequilibran ese debate de dos (y ello sin considerar los problemas que se derivan de la permanente convivencia de éstos con los acusadores y jueces).

Lo paradójico es que en algunos casos este tercero parece ser la más sensata de las voces, y es precisamente su ocasional sensatez la que justifica su permanencia en los debates. La pregunta es: si el Ministerio Público justifica su participación en un debate de partes como "representante de la sociedad" y "el defensor del orden jurídico", ¿para qué, entonces, el juez?

Quienes hayan participado de alguna manera en el tránsito legislativo que se les dio a los anteproyectos preparados por la Comisión Constitucional Redactora creada por el Acto Legislativo 003 de 2002 saben que la permanencia del Ministerio Público en el proceso penal contemporáneo obedeció de manera exclusiva a una exigencia 
política para que pasaran los proyectos en el Congreso, concesión que los promotores debieron hacer a su pesar, so pena de que se hundiera la reforma.

Cuánta más utilidad prestarían al país estos muchos procuradores judiciales (algunos de ellos muy preparados académicamente) si se les destinara como jueces, fiscales o investigadores. Y, lo mejor, el presupuesto existe, porque ya hacen parte de la nómina del Estado.

El proceso penal no necesita garantes diferentes al juez, y si éste falla, para eso existe la segunda instancia e incluso el recurso extraordinario de casación. Nada tiene que hacer el Ministerio Público en el proceso penal actual pues su presencia sólo dilata los procedimientos, rompe el equilibrio de los adversarios y alimenta la burocracia.

Lo mismo ocurre con la figura del representante de víctimas. Nada tiene que hacer un representante de víctimas adicional en el proceso penal cuando, por definición, la Fiscalía es el principal representante de víctimas. Su inconveniente presencia también contribuye a la dilación de los procedimientos y al quebrantamiento del equilibrio que se espera en un debate de contrincantes en igualdad de armas.

Si el ente acusador está convencido de tener un caso y lo presenta ante la jurisdicción, las víctimas ya encontrarán el respaldo que necesitan en sus pretensiones. Lo que no puede ocurrir (y eso es lo que se devela de la jurisprudencia que ha venido autorizando cada vez más su participación) es que bajo la premisa de la deficiencia de la Fiscalía se justifique la presencia del representante de víctimas.

La solución no radica en la proliferación de agentes que intervienen en el proceso y son ajenos a las partes, sino en el fortalecimiento de la Fiscalía y la selección de ciudadanos idóneos en la judicatura.

La representación de víctimas tiene plena justificación en la etapa de indagación preliminar para convencer al ente investigador de que existe un caso, para reclamar el verdadero desarrollo de un trabajo metodológico o incluso para buscar la reapertura de un proceso mal archivado o por la aparición de pruebas sobreviniente. Por supuesto, también para el incidente de reparación integral. Pero fuera de esos escenarios, nada tiene que hacer en el debate reservado para el Estado (representado por la Fiscalía) y el procesado (representado por su defensa técnica).

\section{- Delegación de la persecución penal}

\section{- Acusador privado}

Ya el país ha comprendido la conveniencia de la figura del acusador privado. De allí que se sancionara la Ley 1826 de 2017 (la cual, además, estableció un procedimiento 
penal abreviado que debería revisarse en su mecánica para poderse aplicar a la totalidad de los procesos penales).

A pesar de su sanción jurídica, las estadísticas demuestran que a dos años de su entrada en vigencia esta figura es completamente subutilizada. De allí que, además de una política seria de delegación por parte del acusador, también deben repensarse unas modificaciones legislativas que clarifiquen su aplicación.

Por ejemplo, en el caso de los delitos querellables, no debería ser necesaria la autorización de la Fiscalía y el acusador privado debería poder operar de manera automática.

En el mismo sentido, si bien el legislador no limitó la aplicabilidad a los delitos querellables, sino que la amplió a otro número de infracciones, la accesibilidad a ellos también ha resultado una talanquera en la materialización del espíritu de descongestión que se preveía con la norma.

Así pues, resulta imperioso combinar una determinación concreta de la Fiscalía General de la Nación para hacer uso de esta figura y una reforma legislativa que determine con mayor criterio de unidad qué otros delitos (además de los ya consignados) pueden ser presentados ante la jurisdicción por el representante de víctimas. Por supuesto, el verdadero control del uso racional de la acción penal en manos de particulares que no responden a políticas públicas de instrucción se habrá de soportar en el control material de la acusación que ejerzan los jueces de control de garantía, quienes también deben contar con medidas disciplinarias contundentes contra la presentación de acusaciones temerarias.

\section{$-\quad$ Otros}

Además de estas propuestas concretas (aunque hay muchas más) que parecen ser de buen recibo en la comunidad de litigantes (abogados y fiscales) y que, por supuesto, deben ser objeto de disertaciones democráticas, existen otros puntos que han sido objeto de reciente discusión y merecen mención especial.

\section{- Aforados - Fiscalía}

La figura de los fueros en materia penal supone que algunas dignidades del Estado sean investigadas y juzgadas por determinadas autoridades judiciales con el fin de que éstas garanticen sus derechos en una relación de proporcionalidad jerárquica.

Sin embargo, algo que se concibió como una garantía demostró ser todo lo contrario, de suerte que esa invención constitucional ha resultado frontalmente contradictoria de derechos fundamentales (tanto de rango constitucional como de instrumentos internacionales de derechos humanos), pues en la práctica el fuero vulneraba los 
principios de la división entre la acusación y el juzgamiento y el derecho a la doble instancia o a la impugnación.

Por lo anterior, la Corte Suprema de Justicia intentó remediar los defectos del fuero constitucional a través de modificaciones internas, como también lo hizo el Acto Legislativo 01 de 2018 con la creación de salas de instrucción y de juzgamiento de primera y segunda instancia. Desafortunadamente, dichas soluciones resultan insuficientes en el esfuerzo de subsanar los vacíos del ordenamiento constitucional.

Así las cosas, ¿qué impediría que todas las dignidades (las consignadas en los numerales 3 y 4 del artículo 235 de la Constitución Política) fueran investigadas y acusadas por la Fiscalía General de la Nación (seguramente por fiscales delegados ante la Corte Suprema de Justicia) y acusados ante los tribunales superiores de Distrito Judicial, teniendo como segunda instancia la Sala Penal de la Corte Suprema de Justicia (y como jueces de garantía a jueces del circuito)? Al recurrir a los tribunales superiores de Distrito Judicial, el fuero satisfaría el requisito de proporcionalidad jerárquica sin menoscabar la independencia entre quien acusa (Fiscalía), quien juzga (Tribunal Superior) y ante quien se apela (Corte Suprema de Justicia).

\section{- Privación preventiva de la libertad}

Sobre la privación preventiva de la libertad poco debe decirse en el ámbito normativo pues, salvo la concepción de peligro para la sociedad y para la víctima, la claridad que esbozan las causales de necesidad hace comprensible su restricción a cuestiones netamente procesales. Lo que sí resulta necesario es revisar la causal de peligrosidad para resaltar la independencia del comportamiento peligroso autónomo, de la conducta que está sometiéndose a debate en un proceso penal.

El llamado en este punto está en las instrucciones internas de la Fiscalía y en la pedagogía ciudadana a través de los medios de comunicación. La presunción de inocencia no es cuestión de poca monta; cualquier reclamo de 'justicia' anticipada por vía de la privación preventiva de la libertad es, per se, una injusticia.

Paralelo a esta gran reflexión genérica de racionalización de la detención preventiva, déjese sobre la mesa, y para reflexión del lector, lo conveniente que resultaría proliferar el uso del numeral 8, literal B del artículo 307 de la ley procesal penal vigente, acompañándolo del desarrollo de la figura de los "presta-fianzas" y de los "caza recompensas".

\section{- $\quad$ Preacuerdos y negociaciones / principio de oportunidad}

Como se señaló líneas atrás, en estas fórmulas de terminación anticipada reposa el éxito del sistema procesal penal vigente en Colombia. 
La madurez de un Estado parte del reconocimiento de sus capacidades. Y ningún Estado, por más evolucionado que sea, es capaz de procesar todas las causas penales que lleguen a su conocimiento. En ese sentido, el Estado, responsablemente, debe encaminar sus limitados recursos a la persecución de lo que más aqueja a la sociedad, sin que lo anterior pueda, de ninguna manera, entenderse como un llamado a la impunidad o la desprotección de algunos bienes jurídicos.

Para lograr un equilibrio a partir de esas realidades, las figuras de los preacuerdos, negociaciones y principios de oportunidad resultan las herramientas más idóneas para que el ente persecutor logre que los derechos de las víctimas no se vean desprotegidos sin que tenga que mediar una sentencia condenatoria como consecuencia de un juicio oral.

Pese a lo anterior, estos mecanismos no han sido tan explotados como se pensaba en los albores de la reforma y como así lo demandan las alarmantes cifras ya citadas, veamos ${ }^{4}$ :

\begin{tabular}{|c|c|c|}
\hline Año & Preacuerdos y negociaciones & Principio de oportunidad \\
\hline 2005 & 1152 & 307 \\
\hline 2006 & 2293 & 944 \\
\hline 2007 & 3448 & 1698 \\
\hline 2008 & 3463 & 1101 \\
\hline 2009 & 4203 & 1857 \\
\hline 2010 & 4043 & 1226 \\
\hline 2011 & 5100 & 1178 \\
\hline 2012 & 2900 & 703 \\
\hline 2013 & 1264 & 682 \\
\hline 2014 & 6620 & 509 \\
\hline 2015 & 14.261 & 727 \\
\hline 2016 & 17.857 & 1111 \\
\hline 2017 & 21.795 & 1712 \\
\hline 2018 & 19.872 & 2028 \\
\hline
\end{tabular}

Por lo anterior, habrá que reflexionar sobre todas las trabas legislativas que impiden la aplicación de esas figuras, pero también, y en mayor medida, sobre la disposición

4 Fiscalía General de la Nación. Respuesta a derecho de petición de radicado n. o 20196110164972 , oficio SPPEI-10210. 
de los fiscales de sacarles el provecho debido, pues lo cierto es que su aplicación cada vez surge menos común ${ }^{5}$ :

\section{Sistema Penal Acusatorio}

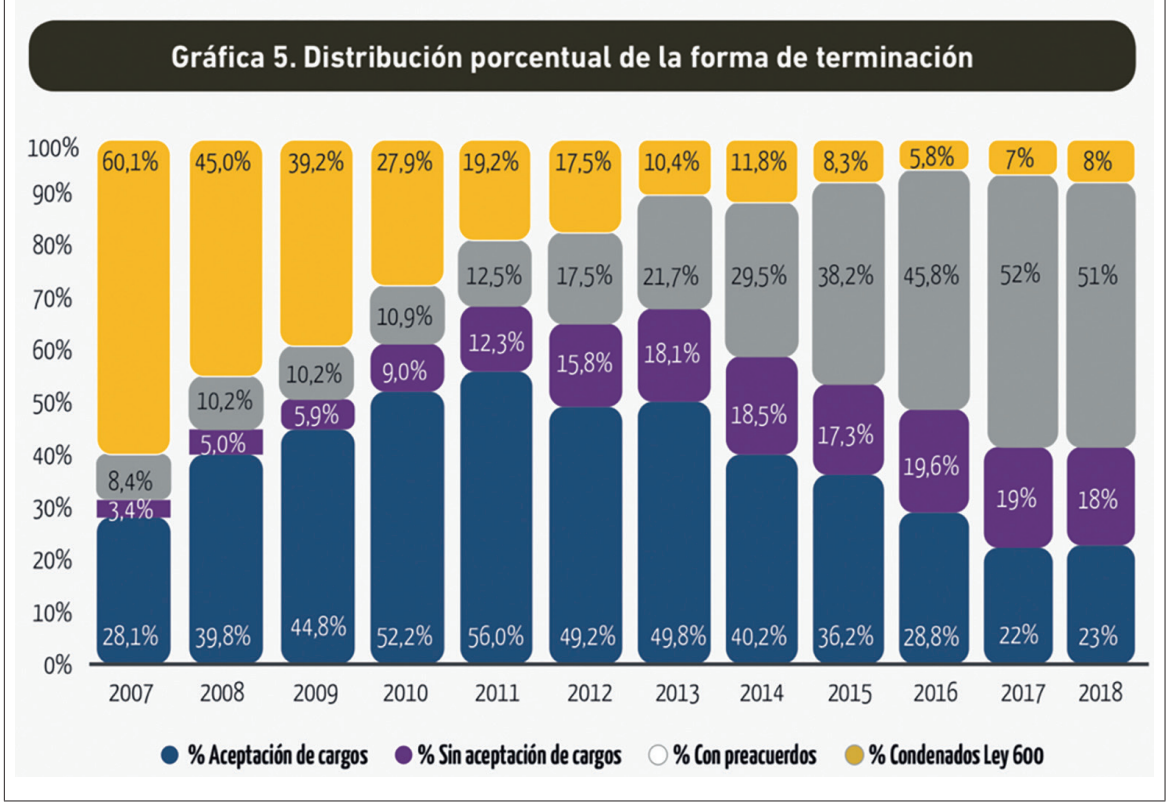

\section{- Penas}

El derecho penal atiende a la determinación de la responsabilidad de un individuo que de manera consciente y voluntaria (o algunas veces por descuido) vulnera una norma penal, lesionando o poniendo en riesgo un bien jurídicamente tutelado, habiendo tenido la posibilidad de encaminar su comportamiento de otra manera.

Al penalmente responsable habrá de reprochársele su conducta, y esto tendrá consecuencias. El gran dilema está en determinar cuándo el Estado simplemente quiere castigar esa conducta y cuándo el Estado debe proteger a la comunidad de un individuo que le representa un riesgo latente. Independientemente de la justificación

5 Consejo Superior de la Judicatura. Informe al Congreso de la República 2018 [en línea] [fecha de consulta: 5 de mayo de 2019]. Disponible en [https://www.ramajudicial.gov.co/documents/1545778/ 5597675/Resumen+Ejecutivo+-+Informe+al+Congreso+de+la+República+2018.pdf/5aed54bb0816-4328-abb7-2681303d441b]. 
conceptual que se aduzca para el castigo, persiste la pregunta de si la privación de la libertad es la única manera como el Estado puede o debe castigar.

Sin duda la respuesta es que no: la privación de la libertad no es ni debe ser la única forma de sanción penal. En ese sentido, el Estado debe convocar al cuerpo legislativo para diseñar una penología que ofrezca variedad de sanciones, reservándose la privación de libertad (y mucho más la intramural) para aquellos individuos que deban ser excluidos de la vida en sociedad para proteger a la comunidad.

\section{- Código Penal}

La trascendencia del derecho penal en el ámbito de los derechos fundamentales de los individuos exige la máxima sencillez normativa posible en la regulación de los delitos y las penas. Las normas penales de una sociedad que respeta la libertad y la dignidad de sus ciudadanos deben ser claras, comprensibles; eso también hace parte de la transparencia del sistema de administración de justicia.

No puede olvidarse que el derecho penal es, en esencia, una garantía de libertad.El ciudadano debe tener la tranquilidad de que mientras no incurra en las conductas expresamente descritas en la ley, nadie podrá atentar contra su libertad.

Así las cosas, también debe propenderse legislativamente a revisar el extenso número de normas que hoy en día componen nuestro estatuto sustantivo y condensar en él -con el mínimo posible de tecnicismo jurídico- todas aquellas conductas que resultan repetitivas y hacerlo de manera que simplifiquen la comprensión del ciudadano común.

\section{- Infraestructura física}

Uno de los mayores retos para la administración de justicia, después del factor humano, es el de mejorar la infraestructura desde donde los jueces ejercen justicia. No se trata solamente de un tema estético o suntuoso, sino de la dignificación de escenarios propios para la materialización de la justicia: lo que sustenta la vida en sociedad. A su vez, una infraestructura adecuada garantiza la materialización de los principios que rigen nuestro derecho penal.

Por ejemplo, es absolutamente inconveniente que los fiscales, que son una parte del proceso, tengan sus despachos en el mismo lugar en donde laboran los jueces. Aunque parezca menor, esta coincidencia en los espacios de trabajo tiene el grave defecto, bien conocido por cualquier abogado litigante, de propiciar una complicidad tácita entre jueces y fiscales que pone en duda la independencia e imparcialidad del juzgador. Recuérdese que cuando de la administración de justicia se trata, el funcionario no sólo debe ser imparcial sino parecerlo. 
Las salas de audiencias han de tener una disposición que permita de manera confiable la práctica probatoria, los registros y hasta la publicidad. Por supuesto, los juzgados deben salvaguardar la posibilidad del acceso al público, pero paralelamente la seguridad física de los jueces y de los demás sujetos procesales.

La lista es grande y de infructuosa presentación en este momento, pues lo realmente importante de este apartado es que la "administración" que opere la rama jurisdiccional e incluso su par en el ente persecutor deben tener como prioridad la procura de recursos públicos y privados para una gran revolución de la planta física de la justicia.

Y si bien ya ha quedado claro que la justicia no tiene ánimo de lucro, también es cierto que la operatividad de ella debe responder a parámetros empresariales eficientes y entre ellos no puede descartarse el de la búsqueda de recursos adicionales que sustenten estas grandes obras más allá del presupuesto estatal, incluyendo fondos internacionales o incluso fuentes derivadas de penas pecuniarias (a propósito de sanciones alternativas) independientes de la reparación de las víctimas.

Todos estos son asuntos que, insisto, deben ponerse sobre la mesa de discusión pública, porque aunque algunos pueden sonar de entrada inviables, lo cierto es que ya están en la agenda de conversación de quienes tienen que habérselas a diario con la justicia. Y si bien un gran número de los reclamos se dirigen a la probidad y capacidad de los funcionarios, no son menores los que apuntan a la ausencia de ingeniería en la administración de justicia.

En este sentido, la reforma que se advierte imperiosa no puede desconocer estos llamados urgentes en materias como las mencionadas y que garantizarán: la concentración de los jueces en su oficio de hacer justicia reservando todo lo administrativo y operativo en los expertos; la reducción de etapas procesales a aquellas que, enalteciendo las garantías, destaquen los debates eminentemente probatorios y terminen la mayor cantidad de procesos de manera anticipada; la limitación de los intervinientes a los postulantes de las tesis adversariales; la concreción el catálogo de infracciones penales al ciudadano común para enaltecer la garantía de la libertad; la reinvención de las penas esperables para los infractores de la ley penal; la modernización de la infraestructura física de la administración de justicia para hacer viables sus principios rectores; etcétera.

\section{REFERENCIAS}

Consejo Superior de la Judicatura. Informe al Congreso de la República 2018 [en línea] [fecha de consulta: 5 de mayo de 2019]. Disponible en [https://www.ramajudicial.gov. co/documents/1545778/5597675/Resumen+Ejecutivo+-+Informe+al+Congreso+de+ la+República+2018.pdf/5aed54bb-0816-4328-abb7-2681303d441b]. 
Fiscalía General de la Nación. Respuesta a derecho de petición de radicado n. ${ }^{\circ}$ 20196110164972 , oficio SPPEI-10210.

Fiscalía General de la Nación. Proporción de noticias según etapa procesal y mes de entrada [en línea] [fecha de consulta: 1. . de mayo de 2019]. Disponible en [https:// www.fiscalia.gov.co/colombia/noticia-criminal/]. 